\title{
Fourth Asian-Pacific Congress of Cardiology
}

The participation of a European at a Congress devoted to Asian-Pacific cardiology must be for him-so I thought-of very limited interest. The cardiological problems facing these countries are different, and the way of conveying them must necessarily be patchy. It was thus with some hesitation that I took part in the Asian-Pacific Congress of Cardiology held in Jerusalem and TelAviv from September 1 to 7, 1968.

The doubts soon proved unfounded. The importance of the Congress was underlined by the two hundred strong American participation with a galaxy of top American cardiologists. Paul White was one of the speakers at the opening session and Jesse Edwards, President of the American Heart Association, and G. E. Burch, President of the American College of Cardiology, were chairmen at various sessions. At the closing session the future of cardiology was discussed by Charles Friedberg, A. Kantrowitz, (replacing Prof. Barnard), Sir John McMichael, the various Asian delegates, with Dr. Neufeld, the organizer of the Congress and President of the Asian-Pacific Cardiac Society, in the chair. Proof of the importance many European centres attached to the meeting was the presence of $F$. Chamberlain, T. N. James, A. M. Masters, Helen Taussig from the U.S.A., Dr. Feifar of W.H.O., Werkö of Sweden, with 37 participants, Snellen of Holland, with 22 participants, Lequime of Belgium, and Wollheim of West Germany.

Sir Kempson Maddox, president of the International Society of Cardiology, whose kind and engaging personality made this meeting so pleasant and informal, presided over many sessions. The meeting on epidemiology underlined the different cardiological problems in Asiatic as compared with European countries. Rheumatic heart disease is still the main problem in India, with a malignant form of mitral stenosis in the forefront causing cardiac failure, pulmonary oedema, and death in children if emergency valvotomy is not performed: 800 such cases were reported by the Indian delegate, and 25 by the Israeli surgeons. Cor pulmonale is the problem in Iran, but its cause was not stated.
Cerebral arteriosclerosis producing haemorrhage and infarction of the brain, divorced from arterial hypertension and the usual metabolic changes found in coronary heart disease, is prevalent in Japan. The increase of coronary disease in the "Westernized" group of population (e.g. late Yemenite immigrants to Israel) formed a sharp contrast, with the total absence of it in the aborigines of New Guinea in whom all the risk factors were missing, a brilliant research presented by an Australian team. Pulseless disease, though first described in Japan, was shown by Dr. Kinare, the Bombay pathologist, to be frequent in India. This was illustrated with clear angiograms and perfect photographs of pathological specimens; the experimental approach suggested that constrictive peri-aortitis (akin to constrictive pericarditis), possibly of tuberculous origin, may be the cause of this mysterious illness.

The main interest centred on aortic valve surgery. The report of 546 homograft replacements by Barratt-Boyes of New Zealand (population 2.5 millions) and his team with a total late mortality of 13 per cent suggests that prosthetic valve surgery in aortic valve disease, except in the old when it can be performed more quickly, will soon become obsolete unless a prosthetic valve is invented which will better resist buffeting and will not cause thromboembolism and haemolysis. Heterografts of sheep, pig, and calf valves was another promising approach, now beyond the experimental stage.

There were many British contributions. The ones particularly appreciated were the round-table discussions on intensive care units (Oliver, Shillingford), on cardiomyopathy (Brigden, Emanuel, Goodwin, presided over by G. E. Burch), and on antiarrhythmic drugs ( $M$. Thomas). A notable feature was the high standard of British presentation, derived from the strict training ground of British Cardiac Society meetings. There were many other interesting presentations of high standard contributed by representatives of countries in the Far East.

A last word on the social programme. The reception given by the Mayor of Jerusalem in the patio 
of the Museum under a starlit sky, the subsequent visit to the Museum, the closing banquet around the swimming pool of the Tel-Aviv Hilton, with flower baskets, carrying flames, slowly drifting over the water in the night breeze, were unforgetable occasions. Oriental courtesy required that all important participants should deliver a short address and the dozen or so speeches unduly prolonged the evening. Our President was asked twice to the dais and extended, in the second speech, the invitation to all participants to the World Con- gress of Cardiology in 1970. It will be difficult to emulate the perfect planning and success of this Congress which was due to the hard work of Prof. Neufeld and his team. After a guided tour of old Jerusalem, the 800 participants were transferred in a convoy of coaches from Jerusalem to Tel-Aviv (a distance of 60 miles); that each participant found his baggage in his hotel room on arrival in TelAviv was the crowning feat of organization!

CoRnelio Papp 